\title{
Feasibility of Basket Technique Compared to the Office Hysteroscopy to Treat Endometrial Polyps in Patients Undergoing In Vitro Fertilization
}

\author{
SŞahin ZETEROĞLUa, \\ (1) AșKı ELLIBBEŞ KAYA \\ (1) Alper BAŞBUG ${ }^{b}$, \\ (1) Yiğit ÇAKIROĞLUc, \\ (D) Ozan DOĞANd, \\ - Eray ÇALIȘKANe
}

aDepartment of Obstetrics and Gynecology, Acıbadem University Health Services Vocational School,

Bursa, TURKEY

bDepartment of Obstetrics and Gynecology, Düzce University Health Practice and Research Hospital,

Düzce, TURKEY

'Department of Obstetrics and Gynecology, Kocaeli University Faculty of Medicine,

Kocaeli, TURKEY

${ }^{d}$ Clinic of Obstetrics and Gynecology,

İstanbul Şişli Hamidiye Etfal Training and

Research Hospital,

İstanbul, TURKEY

eDepartment of Obstetrics and Gynecology, Bahçesehir University Faculty of Medicine, Kocaeli, TURKEY

Received: 10.07.2018

Received in revised form: 05.09.2018

Accepted: 07.09.2018

Available online: 15.01.2019

Correspondence:

Ozan DOĞAN

İstanbul Şişli Hamidiye Etfal Training and

Research Hospital,

Clinic of Obstetrics and Gynecology,

İstanbul, TURKEY

ozandogan02@ hotmail.com

Copyright (C 2018 by Türkiye Klinikleri

\begin{abstract}
Objective: The authors aim to compare the results of office hysteroscopic basket polypectomy with operative hysteroscopy in endometrial polyps detected prior to in vitro fertilization (IVF). Material and Methods: Infertile patients, who underwent polypectomy before treatment, were analyzed retrospectively. Patients who underwent basket polypectomy as office hysteroscopy (Group 1, n=55) and hysteroscopic polypectomy (Group 2, $\mathrm{n}=49$ ) were included in the study. Demographic data, operation time, success rates, and pregnancy rates after operation were compared between the two groups. Results: The mean operating time for Group 1 was 14.98 $\pm 3.67 \mathrm{~min}$, while that for Group 2 was $18.84 \pm 3.30 \mathrm{~min}$ ( $\mathrm{p}=0.001$ ). The success rates between the groups were similar ( $96.3 \%$ vs. $100 \%$; $\mathrm{p}=0.652$ ), without any major complications. Further, the biochemical (52.7\% vs. $48.9 \%$, OR 1.19; $95 \%$ CI: 0.55-2.59; $\mathrm{p}=0.696)$, clinical ( $43.6 \%$ vs. $40.8 \%$, OR 1.16; $95 \%$ CI: $0.52-2.59$; $\mathrm{p}=0.712$ ), ongoing pregnancy ( $38.1 \%$ vs. $34.6 \%$, OR 1.21 ; $95 \%$ CI: 0.52 2.81; $\mathrm{p}=0.647$ ), live births ( $34.5 \%$ vs. $28.6 \%$, OR 1.3116; $95 \%$ CI:0.57-3.03; $\mathrm{p}=0.514$ ), early spontaneous miscarriage (5.5\% vs. 6.1 , OR $0.88 ; 95 \%$ CI: $0.17-4.60 ; \mathrm{p}=0.884)$ and spontaneous pregnancy (5.5 vs. 4.1 , OR $0.745 ; \% 95$ CI: $0.21-8.4 ; \mathrm{p}=0.745$ ) rates after polypectomy were observed to be similar in both the groups. Conclusion: Hysteroscopic basket polypectomy was not inferior to operative hysteroscopy regarding success rates and was found to be superior in terms of operating time in patients planning in vitro fertilization.
\end{abstract}

Keywords: Basket polypectomy; endometrial polyps; in vitro fertilization (IVF); office hysteroscopy; polypectomy

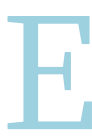
ndometrial polyp, an organic pathology, is frequently encountered in gynecological practice, with an incidence of 7\%-35\%. ${ }^{1}$ It is one of the most common reasons for abnormal uterine bleeding. ${ }^{2}$ The presence of endometrial polyp is an important factor in infertile patients. Endometrial polyps may cause abnormal uterine bleeding, mechanical obstruction of sperm pathway, inflammatory endometrial response, disruption of uterine receptivity, embryo implantation and thereby resulting in infertility. ${ }^{3,4}$ It is claimed that endometrial polyps disrupt endometrial receptivity by causing a decrease in insulin-like growth factor 1 binding protein (IGFBP-1) and glycodelin levels. ${ }^{3,4}$ Endometrial polyps have been reported in $32 \%$ infertile couples. ${ }^{5}$ Numerous studies examining the increase in spontaneous pregnancy rate after polypectomy have been undertaken ${ }^{5,6,7}$. Although some studies certify that pregnancy rate would increase after polypectomy, there are other debates regarding the necessity of polypectomy when endometrial polyps are detected during IVF cycle. ${ }^{6,8-11}$ 
Polypectomy can be performed by the traditional operative hysteroscopy. This utilizes hysteroscopes of different diameters, and it is performed, under anesthesia, by cervical dilation. On the other hand, office hysteroscopy is performed in office standards without any need of cervical dilatation and anesthesia; instead, it requires smaller diameter hysteroscopes. Endometrial polyps can be removed during office hysteroscopy. ${ }^{12,13}$ However, the fragile structure of polyps and small diameter instruments can make this process difficult. During the this process, polyps from the uterine cavity may fragment, and the number of reentry-exits into the cavity may increase resulting in a longer duration. ${ }^{14}$ In urology practice, Basket method has been used for the removal of the ureter, kidney, and bladder calculu. ${ }^{15}$ The basket can be placed comfortably into the cavity as it easily advances from the instrument part of the hysteroscope and can be opened at any time. Basket polypectomy provides the advantage of polypectomy without fragmentation, by entering into the uterine cavity at once and collecting the whole polyp into the basket.

The purpose of this study is to investigate the effects of basket polypectomy as a new method in contrast to office hysteroscopy before IVF treatment.

\section{MATERIAL AND METHODS}

This retrospective case-control study considered the records of patients who underwent polypectomy before IVF treatment, between March 2013 and March 2017 in Kocaeli Medical Park Hospital and Bursa Acibadem Hospital. Before IVF treatment, hysteroscopy was scheduled for endometrial polyps, which were identified by transvaginal sonography, performed during the third to the fifth day of the menstrual period. Office hysteroscopic basket polypectomy and operative hysteroscopy were performed in both the hospitals. The annual IVF success rates of both the hospitals are similar. The choice of performing hysteroscopy via basket polypectomy or operative method was made considering the equipment compliance, detected polyp size and patient consent.
The patients less than 40 years of age, who underwent hysteroscopic polypectomy one month before IVF treatment with four or fewer polyps measuring maximum $25 \mathrm{~mm}$ and patients who underwent polypectomy one-month before IVF were included in the study. Surgeries were carried out by two physicians having an experience of 15 years in hysteroscopy.

Office procedures were conducted using rigid office hysteroscopes having $18^{\circ}$ viewing angle, $5 \mathrm{~F}$ enabling surgical operation with $4.4 \mathrm{~mm}$ outer diameter (Karl Storz GmbH \& Co., Tuttlingen, Germany). The applicator was moved from the instrument part and the basket, consisting of 4 thin wires, could be opened at any time and place. The baskets used in the study were $120 \mathrm{~cm}$ in length, $3 \mathrm{~F}$ in outer diameter and could be opened up to $1.6 \mathrm{~mm}$ (Boston Scientific, USA) (Figure 1).

Monopolar conventional resectoscopes with 8 $\mathrm{mm}$ outer diameter and $30^{\circ}$ viewing angle were used in the operative hysteroscopy group (Karl Storz GmbH \& Co., Tuttlingen, Germany). While, in the office hysteroscopy group, polyps were removed using a basket method with the help of cold microscissors without consuming any power. None of the patients in the basket polypectomy group experienced any interruption due to pain or loss of tolerability during the procedure. Study subjects were discharged on the same day, two hours after the procedure, antibiotics, and NSAID were prescribed, and none of them returned to the hospital with complaints of bleeding or pain.



FIGURE 1: A- An opened view of the basket used for polypectomy, B- The image of operative hysteroscopy before polypectomy, C- The image of polypectomy performed with a basket. 
A total of 148 women were recruited for the study. Thirty-nine patients (37.5\%) were excluded from the study as they either had a polyp of more than $25 \mathrm{~mm}$ or had five or more polyps. Two (1.92\%) of the remaining 109 patients were shifted from office hysteroscopy to operative hysteroscopy due to submucous myoma; one $(0.96 \%)$ did not come for follow up, and two (1.92\%) started IVF treatment after two cycles and were therefore excluded. As a result, 55 patients $(52.88 \%)$ were left in basket polypectomy group (Group 1), and 49 patients $(47.12 \%)$ were left in operative hysteroscopy group (Group 2). Figure 2 depicts the patient selection flow chart.

Patients' age, height, weight, body mass index (BMI), infertility times, primary and secondary infertility rates, operation techniques, operation time, number of polyps detected and polyp sizes were recorded. On the fourteenth day after IVF, pregnancy was considered to be posi-

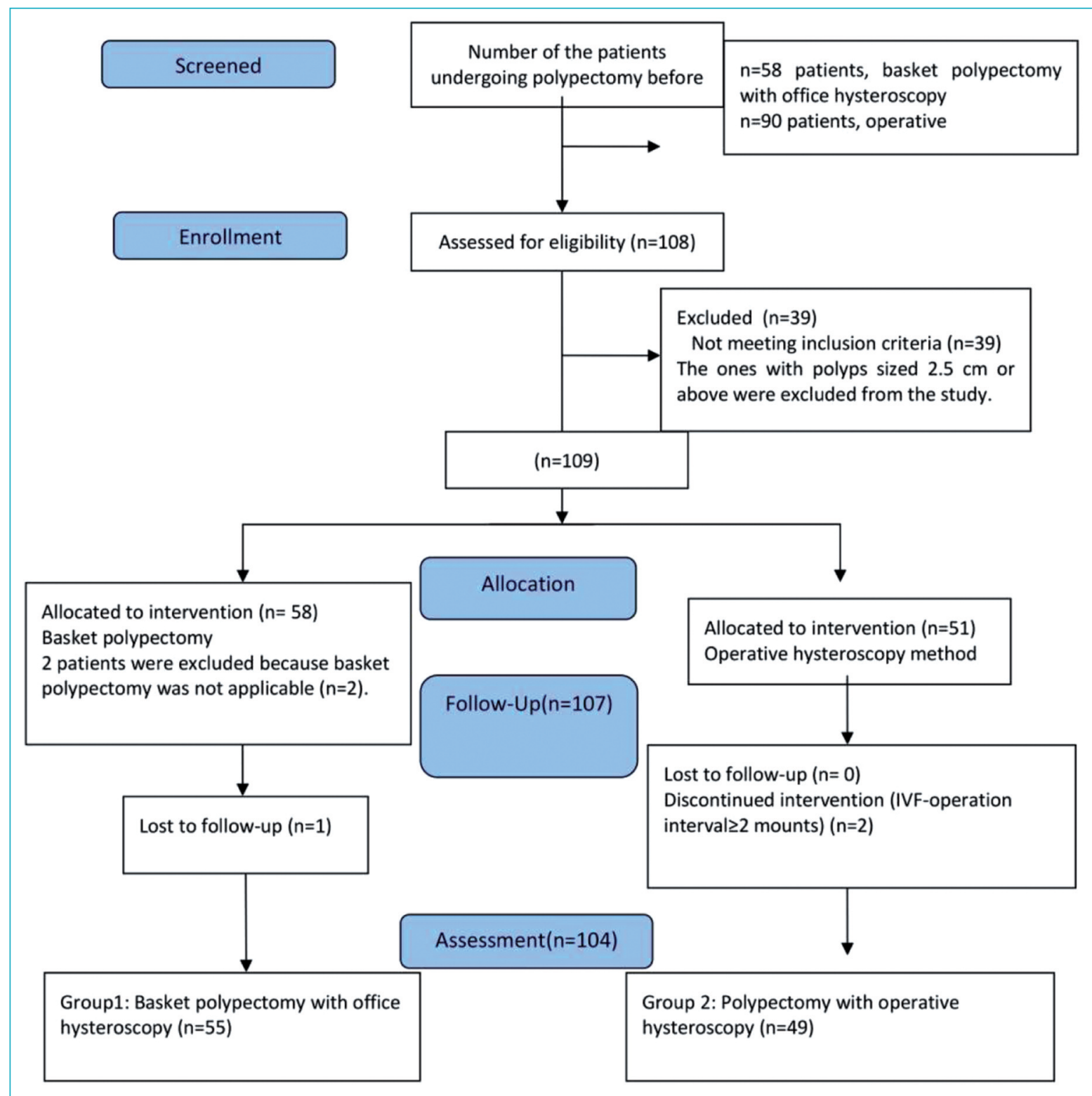

FIGURE 2: The patient selection flow chart. 
tive if $\beta$-HCG was $\geq 30 \mathrm{IU} / \mathrm{mL}$; clinical pregnancy was confirmed if gestational sac was observed during the fifth week. Ongoing pregnancy was defined as a pregnancy lasting more than 12 weeks and early pregnancy loss was defined as miscarriage before 12 weeks of pregnancy. After polypectomy, if a patient became pregnant spontaneously before IVF, it was recorded as spontaneous pregnancy. Previous IVF numbers, biochemical pregnancy rates, clinical pregnancies, early pregnancy loss rates, live birth rates, and spontaneous pregnancy rates after polypectomy were also recorded.

The present study primarily aimed to determine whether or not there were differences between the operation times in basket polypectomy and conventional hysteroscopic polypectomy. The secondary outcome was to evaluate the effects of these methods on pregnancy results.

\section{ETHICAL APPROVAL}

Ethical approval for this study was obtained from the Ethics Committee, Duzce University (approval number 2017-148). All procedures performed in the studies involving human participants were in accordance with the ethical standards of the institutional and/or national research committee and followed the 1964 Helsinki Declaration and its later amendments or comparable ethical regulations.

\section{STATISTICAL ANALYSIS}

Statistical analyses were performed using the Statistical Package for Social Sciences for Windows 22.0 software (SPSS, Chicago, IL., USA). Descriptive statistics were inferred as the mean, standard deviation, frequency, and percentage. ShapiroWilk test was utilized to check the normality of continuous variables. Parametric comparisons were performed using Student's t-test for normally distributed continuous data, and non-parametric comparisons were performed using the Mann-Whitney U test for non- normal continuous data distribution. Categorical variables were compared using chi-square or Fisher's exact tests, as appropriate. Univariate Binary Logistic Regression analysis was used to determine the efficacy of the surgical pro- cedure on pregnancy rates. Statistical significance was defined as $\mathrm{p}<0.05$.

\section{RESULTS}

The mean age of the patients was $33.23 \pm 4.78$ years in Group 1 and $32.19 \pm 4.52$ years in Group 2. Regarding age, BMI, duration of infertility, infertility types, and causes, the groups were not statistically different (Table 1).

Office hysteroscopic basket polypectomy was successfully performed in five patients (96\%) and failed in only two (3.5\%) patients. These patients had broad-based, 2 and $2.5 \mathrm{~mm}$ endometrial polyps, respectively, thus underwent operative hysteros copy. On the other hand, in Group 2, all polyps were removed successfully. The success rates were, however, similar in both the groups ( $\mathrm{p}=0.652)$.

No major complication was observed in any of the groups.

The size of the polyps removed using office hysteroscopic basket polypectomy, and operative

\begin{tabular}{|c|c|c|c|}
\hline & $\begin{array}{c}\text { Group } 1 \\
n=55\end{array}$ & $\begin{array}{c}\text { Group } 2 \\
n=49\end{array}$ & $p$ value \\
\hline Age (years) & $33.23 \pm 4.78$ & $32.19 \pm 4.52$ & 0.424 \\
\hline BMI & $24.47 \pm 2.91$ & $25.03 \pm 5.13$ & 0.422 \\
\hline Infertility duration (month) & $63(12-144)$ & $66(24-180)$ & 0.740 \\
\hline \multirow{2}{*}{$\begin{array}{l}\text { Previous IVF } \\
\text { count- median (min-max) }\end{array}$} & $1(0-6)$ & $1(0-5)$ & 0.652 \\
\hline & $\begin{array}{c}\text { Group } 1 \\
n=55\end{array}$ & $\begin{array}{c}\text { Group } 2 \\
n=49\end{array}$ & $p$ value \\
\hline \multicolumn{4}{|l|}{ Infertility type } \\
\hline Primary & $50(90.9 \%)$ & $41(83.7 \%)$ & 0.345 \\
\hline Secondary & $5(9.1 \%)$ & $8(16.3 \%)$ & 0.405 \\
\hline \multicolumn{4}{|l|}{ Infertility causes* } \\
\hline Male & $20(36.4 \%)$ & $13(26.5 \%)$ & 0.223 \\
\hline Tubal & $12(21.8 \%)$ & $8(16.3 \%)$ & 0.445 \\
\hline Ovarian & $10(18.2 \%)$ & $8(16.3 \%)$ & 0.720 \\
\hline Unexplained & $13(23.6 \%)$ & $20(40.8 \%)$ & 0.223 \\
\hline
\end{tabular}

Group 1: IVF after basket polypectomy,

Group 2: IVF after operative hysteroscopy.

Statistical significance is defined as $p \leq 0.05$

*Some women had more than one cause of infertility.

Data are shown as mean $\pm \mathrm{SD}$, median (min-max) or frequency $(\%)$. 
hysteroscopic polypectomy ranged from 7 to 21 $\mathrm{mm}$ and 7 to $24 \mathrm{~mm}$, respectively. The differences in polyp sizes between the groups were not statistically significant $(\mathrm{p}=0.07)$. The median number of polyps removed was 1 (min-max; $1-3$ and $1-4 ; \mathrm{p}=$ 0.869 ). The median number of IVF performed previously was 1 (min-max; $0-6$ and $0-5 ; \mathrm{p}=0.652$ ), and no statistically significant difference was found in this regard between the groups. The mean duration of office hysteroscopic basket polypectomy was $14.98 \pm 3.67 \mathrm{~min}$, while that of operative hysteroscopic polypectomy was $18.84 \pm 3.30 \mathrm{~min}$. The mean operation time was statistically and significantly shorter in basket polypectomy method $(\mathrm{p}=0.001$; Table 2).

On evaluating the efficacy of basket polypectomy and operative hysteroscopic polypectomy on pregnancy outcomes, the biochemical (52.7\% vs. 48.9\%, OR 1.19; 95\% CI: 0.55-2.59; $\mathrm{p}=0.696$ ), clinical (43.6\% vs. $40.8 \%$, OR 1.16 ; $95 \%$ CI: $0.52-2.59$; $\mathrm{p}=0.712$ ), ongoing pregnancy ( $38.1 \%$ vs. $34.6 \%$, OR 1.21; 95\% CI: 0.52-2.81; $\mathrm{p}=0.647$ ) and live birth (34.5\% vs. $28.6 \%$, OR 1.3116 ; 95\% CI:0.57-3.03; $\mathrm{p}=0.514$ ) rates were not found to be statistically significant between the groups (Table 3). Early spontaneous miscarriage ( $5.5 \%$ vs. 6.1 , OR 0.88 ; $95 \% \mathrm{CI}$ : 0.17-4.60; $\mathrm{p}=0.884$ ) and spontaneous pregnancy (5.5 vs. 4.1 , OR $0.745 ; \% 95$ CI: $0.21-8.4 ; \mathrm{p}=0.745$ ) rates after polypectomy were observed to be similar in both the groups.

\begin{tabular}{|lccc|}
\hline \multicolumn{4}{|c|}{ TABLE 2: Operation time, number and size of the } \\
extracted polyps \\
\hline \multicolumn{4}{|c}{ Group 1 } \\
$\mathrm{n}=55$ & Group 2 \\
& $1(1-3)$ & $1(1-4)$ & 0.869 \\
Number of extracted & & & \\
polyps (min-max) & $11.73 \pm 2.1(7-21)$ & $12.84 \pm 39(7-24)$ & 0.070 \\
$\begin{array}{l}\text { Polyp's maximum diameter } \\
\text { (mm, mean } \pm \text { SD min-max) }\end{array}$ & & \\
$\begin{array}{l}\text { Operation time (minute) } \\
\text { Success rate; } n \text { (\%) }\end{array}$ & $14.98 \pm(10-25)$ & $18.84 \pm(12-26)$ & 0.001 \\
\hline
\end{tabular}

Group 1: IVF after basket polypectomy,

Group 2: IVF after operative hysteroscopy.

Statistical significance is defined as $p \leq 0.05$.

Data are shown as median (min-max).

\section{DISCUSSION}

Data obtained in the study reveals that the method of basket polypectomy shortens the operating time and it is not inferior in terms of success rates.

The main purpose of uterine cavity evaluation, during the assessment of infertile patients, is to identify and treat space-occupying lesions and structural abnormalities causing implantation failure before the treatment. Hysterosalpingography (HSG) is the most commonly used method in the evaluation of infertile patients in terms of tubal patency and uterine pathology; nevertheless, it is known that HSG has high chances of giving false negative results in the uterine cavity. ${ }^{16}$ Sonohysterography, a special ultrasonographic technique, is also preferred because of better applicability than HSG and since it provides more accurate information about the cavity. ${ }^{17}$ Hysteroscopy, which is the main topic of the study, is the gold standard method for evaluation of the uterine cavity, and is preferred in patients with abnormal uterine bleeding; it is frequently used for assessing infertile patients and patients suspected of pathology in the cavity. ${ }^{1,13,18}$ There are some clinics which prefer office hysteroscopy only in cases suspicious of endometrial pathology as it is routinely used for the evaluation of the cavity before IVF. A study conducted by Mouhayar et al. in 2017 concluded that office or operative hysteroscopy performed before an infertility treatment is a cost-effective means of increasing pregnancy rate. ${ }^{19}$ In a randomized controlled study conducted by Elsetohy et al. in 2015, the pregnancy rate was found to be significantly higher after routine office hysteroscopy but before ICSI in comparison to that without hysteroscopy. ${ }^{20}$

Yang et al. in 2017 compared the patients who underwent hysteroscopic polypectomy before IVF and the patients who were not evaluated for the cavity and reported that the embryo transfer rates were similar in polypectomy group, while clinical pregnancy rates were significantly higher. ${ }^{21}$ Karayalcin et al. in 2012 proved that the office hysteroscopy performed two months before embryo transfer increased pregnancy rates, im- 


\begin{tabular}{|c|c|c|c|c|}
\hline \multicolumn{5}{|c|}{ TABLE 3: Pregnancy results. } \\
\hline Pregnancy outcomes & Group $1 \mathrm{n}=55$ & Group $2 \mathrm{n}=49$ & Odds ratio $(95 \% \mathrm{Cl})$ & $p$ value \\
\hline Biochemical pregnancy (\%) & $29(52.7 \%)$ & $24(48.9 \%)$ & $1.19(0.55$ to 2.59$)$ & 0.696 \\
\hline Clinical pregnancy (\%) & $24(43.6 \%)$ & $20(40.8 \%)$ & $1.16(0.52$ to 2.59$)$ & 0.712 \\
\hline Early spontaneous miscarriage (\%) & $3(5.5 \%)$ & $3(6.1 \%)$ & $0.88(0.17$ to 4.60$)$ & 0.884 \\
\hline Ongoing pregnancy (\%) & $21(38.1 \%)$ & $17(34.6 \%)$ & $1.21(0.52$ to 2.81$)$ & 0.647 \\
\hline Live birth (\%) & $19(34.5 \%)$ & $14(28.6 \%)$ & $1.31(0.57$ to 3.03$)$ & 0.514 \\
\hline Spontaneous pregnancy after polypectomy (\%) & $3(5.5 \%)$ & $2(4.1)$ & $1.35(0.21$ to8.40) & 0.745 \\
\hline
\end{tabular}

Group 1: IVF after basket polypectomy, Group 2: IVF after operative hysteroscopy. $\mathrm{P} \leq 0.05$ is statistically significant, Data are shown as frequency (\%).

plantation rates and live birth rates. ${ }^{11}$ The participants of the study underwent general pelvic examination during the second to fifth day of the menstrual period and pelvic organ examination using transvaginal sonography; the cavity was evaluated, and the patients suspected of pathology underwent hysteroscopy. In terms of pregnancy outcomes, pregnancy rates were found to be higher in the basket method, although it was not statistically significant. Currently, there are studies suggesting IVF without polypectomy. ${ }^{21,22}$ In the present study, it was not surprising that there was no significant difference in pregnancy outcomes between the two polypectomy methods.

The authors have been using the basket, which is originally preferred in the urology department, for office hysteroscopic polypectomy procedure since 2013. The present study emphasizes this new method in hysteroscopic polypectomy which can be applied in offices without anesthesia. There are many advantages of office hysteroscopic procedure over operative hysteroscopy. Some of the most important advantages include patient satisfaction, a decrease in physician and patient's stress and lower cost. . $^{12,14,23}$

Sudano et al. in 2016 defined an operating procedure for their own device called REP-b (Hysterobasket), which was inspired by the Dormia basket used by the urologists; the authors utilized it in the present study. ${ }^{14}$ This device was designed to be smaller, as for the endometrial cavity and was well adaptive to hysteroscopy. In the study by Sudano et al., hysterobasket was applied to 70 patients (aged 32-83 years) with endometrial pathology. In the Control group with 70 patients, polyps were taken out of the body using microforceps during office hysteroscopy. Operating time was significantly reduced in the hysterobasket group. Similarly, in the present study, the operating time was observed to be significantly shorter as compared to that of the operative hysteroscopy procedure. Invasive drug treatment, financial burden, long-term treatment, and unpredictable results already cause more stress to the patients during IVF treatment. However, simultaneous treatments can be successful with this method without offering any additional surgery and anesthesia. As Sudano et al. mentioned in their study, it is not always possible to perform an operative intervention with office hysteroscopy. ${ }^{14}$ A polyp, which is cut at the base using scissors, fragments during the extraction with microforceps requires frequent entry-exit to the uterine cavity. However, in officebased polypectomy, the type of tissue is fragile or hard, and thus the frequency of entry and exit from the cervical canal is increased; it leads to prolongation of the operating time and decreases patient comfort. Therefore, the need for hysteroscopic basket emerges. The hysteroscopic basket can remove the polyp at once even if it is bigger than the basket diameter, the operating time shortens and patient satisfaction increases. In some cases, the polyp can be cut from the base using cold micro scissors even before the use of basket, making the removal easier. One of the differences between the two groups that participated in the study was the use of energy modalities. Hysteroscopic energy modality was not used in Group 1 and it is not exactly known whether or not the use of energy modality affects endometrial receptivity. Prospective randomized controlled studies are required to establish this fact. 
The limitations of the present study include the retrospective nature of the study, lack of power calculation, a limited number of cases, and the fact that the groups were not evaluated for pain.

It can be concluded that hysteroscopic basket polypectomy is not inferior in terms of success rates and superior to operative hysteroscopy in terms of operating time in patients planning in vitro fertilization. The authors believe that with prospective randomized controlled trials and further development and usage dissemination of the device could increase proferens by more clinicians.

\section{Acknowledgments}

We would like to thank our assistant health workers, especially our nurse friends, who work in our IVF centers for their support in this study.

\section{Source of Finance}

During this study, no financial or spiritual support was received neither from any pharmaceutical company that has a direct connection with the research subject, nor from a company that provides or produces medical instruments and materials which may negatively affect the evaluation process of this study.

\section{Conflict of Interest}

No conflicts of interest between the authors and / or family members of the scientific and medical committee members or members of the potential conflicts of interest, counseling, expertise, working conditions, share holding and similar situations in any firm.

\section{Authorship Contributions}

Idea/Concept: Şahin Zeteroğlu, Aşkı Ellibeş Kaya, Eray Çalışkan; Design: Alper Başbuğ, Aşkı Ellibeş Kaya, Yiğit Çakıroğlu, Ozan Doğan; Control/Supervision: Yiğit Çakıroğlu, Ozan Doğan; Data Collection and/or Processing: Şahin Zeteroğlu, Aşkı Ellibeş Kaya, Eray Çalışkan, Yiğit Çakıroğlu, Ozan Doğan; Analysis and/or Interpretation: Alper Başbuğ; Literature Review: Yiğit Çakıroğlu, Ozan Doğan; Writing the Article: Aşkı Ellibeş Kaya; Critical Review: Eray Çalışkan; References and Fundings: Alper Başbuğ, Yiğit Çakıroğlu, Ozan Doğan.

\section{REFERENCES}

1. American Association of Gynecologic Laparoscopists. AAGL practice report: practice guidelines for the diagnosis and management of endometrial polyps. J Minim Invasive Gynecol 2012;19(1):3-10.

2. Dreisler E, Stampe Sorensen S, Ibsen $\mathrm{PH}$, Lose G. Prevalence of endometrial polyps and abnormal uterine bleeding in a Danish population aged 20-74 years. Ultrasound Obstet Gynecol 2009;33(1):1028.

3. Elbehery MM, Nouh AA, Mohamed ML, Alanwar AA, Abd-Allah SH, Shalaby SM. Insulinlike growth factor binding protein-1 and glycodelin levels in uterine flushing before and after hysteroscopic polypectomy. Clin Lab 2011;57(11-12):953-7.

4. Donaghay M, Lessey BA. Uterine receptivity: alterations associated with benign 591 gynecological disease. Semin Reprod Med 2007;25(6):461-75.

5. Hinckley MD, Milki AA. 1000 office-based hysteroscopies prior to in vitro fertilization: feasibility and findings. JSLS 2004;8(2):1037.

6. Shokeir TA, Shalan HM, El-Shafei MM. Significance of endometrial polyps detected hysteroscopically in eumenorrheic infertile women. J Obstet Gynaecol Res 2004;30(2): 84-9.

7. Stamatellos I, Apostolides A, Stamatopoulos $\mathrm{P}$, Bontis J. Pregnancy rates after hysteroscopic polypectomy depending on the size or number of the polyps. Arch Gynecol Obstet 2008;277(5):395-9.

8. Kodaman PH. Hysteroscopic polypectomy for women undergoing IVF treatment: when is it necessary? Curr Opin Obstet Gynecol 2016;28(3):184-90.

9. Pérez-Medina T, Bajo-Arenas J, Salazar $F$, Redondo T, Sanfrutos L, Alvarez P, et al. Endometrial polyps and their implication in the pregnancy rates of patients undergoing intrauterine insemination: a prospective, randomized study. Hum Reprod 2005;20(6): 1632-5.

10. Yang JH, Yang PK, Chen MJ, Chen SU, Yang YS. Management of endometrial polyps incidentally diagnosed during IVF: a case-control study. Reprod Biomed Online 2017;34(3):28590.

11. Karayalçin R, Ozyer S, Ozcan S, Uzunlar O, Gürlek B, Moraloğlu $\mathrm{O}$, et al. Office hysteroscopy improves pregnancy rates following IVF. Reprod Biomed Online 2012;25(3):261. 6.
12. Dealberti D, Riboni F, Cosma S, Pisani C, Montella F, Saitta S, et al. Feasibility and 570 acceptability of office-based polypectomy with a $16 \mathrm{~F}$ mini-resectoscope: a multicenter clinical study. J Minim Invasive Gynecol 2016;23(3):418-24.

13. Di Spiezio Sardo A, Di Carlo C, Minozzi S, Spinelli M, Pistotti V, Alviggi C, et al. Efficacy of 532 hysteroscopy in improving reproductive outcomes of infertile couples: a systematic review 533 and metaanalysis. Hum Reprod Update 2016;22(4): 479-96.

14. Sudano MC, Vitale SG, Rapisarda AM, Carastro D, Tropea A, Zizza G. The REP-b (removal of endometrial pathologies-basket) in-office hysteroscopy. Updates Surg 2016;68(4):40712.

15. Dormia G, Minervini MS, Malagola G, Bertana $F$, Gonnella $G$, Mazza L, et al. [The basquet in day hospital]. Arch Ital Urol Androl 1998;70(3):131-2.

16. Golan A, Eilat E, Ron-El R, Herman A, Soffer Y, Bukovsky I. Hysteroscopy is superior to hysterosalpingography in infertilityinvestigation. Acta Obstet Gynecol Scand 1996;75(7): 654-6. 
17. Bittencourt CA, Dos Santos Simões R, Bernardo WM, Fuchs LFP, Soares Júnior JM, Pastore AR, et al. Accuracy of saline contrast sonohysterography in detection of endometrial polyps and submucosal leiomyomas in women of reproductive age with abnormal uterine bleeding: systematic review and metaanalysis. Ultrasound Obstet Gynecol 2017;50 (1):32-9.

18. Bosteels J, Kasius J, Weyers S, Broekmans FJ, Mol BW, D'Hooghe TM. Hysteroscopy for treating subfertility associated with suspected major uterine cavity abnormalities.
Cochrane Database Syst Rev 2015;21(2): CD009461.

19. Mouhayar Y, Yin O, Mumford SL, Segars JH. Hysteroscopic polypectomy prior to infertility treatment: a cost analysis and systematic review. Eur J Obstet Gynecol Reprod Biol 2017;213:107-15.

20. Elsetohy KA, Askalany AH, Hassan M, Dawood Z. Routine office hysteroscopy prior to ICSI vs. ICSI alone in patients with normal transvaginal ultrasound: a randomized controlled trial. Arch Gynecol Obstet 2015;291(1):193-9.

21. Ghaffari $F$, Arabipoor A, Bagheri Lankarani $N$, Hosseini F, Bahmanabadi A. Hysteroscopic polypectomy without cycle cancellation in IVF/ICSI cycles: a cross-sectional study. Eur J Obstet Gynecol Reprod Biol 2016;205:3742.

22. Tiras B, Korucuoglu U, Polat M, Zeyneloglu $H B$, Saltik A, Yarali H. Management of endometrial polyps diagnosed before or during ICSI cycles. Reprod BioMed Online 2012;24(1):123-8.

23. Kremer C, Duffy S, Moroney M. Patient satisfaction with outpatient hysteroscopy versus day case hysteroscopy: randomized controlled trial. Br Med J 2000;29(7230):279-82. 